in der Verdünnung. Nach Ablauf derselben wurde wieder abgehebert, verdünnt, stehen gelassen, abgehebert und diese Procedur so oft wiederholt, bis sich die ganze Schmutzmenge in reinem Wasser befand. Nachdem dies erreicht war, wurde nochmals bis auf $100-150 \mathrm{cc}$ abgehebert, der Schmutz auf tarirtem Filter gesammelt, getrocknet und gewogen. Da die Schmutzstoffe nicht trocken in die Milch gelangen, so muss man dieselben auf wasserhaltige Substanz umrechnen. Renk fand in Kuhkoth $87 \%$ Wasser. Nimmt man an, dass der in die Milch gelangende Koth doch wohl bereits etwas abgetrocknet ist, so wird am besten ein Wassergehalt von $80 \%$ angenommen werden können. Man würde also das Fünffache des gefundenen Trockenschmutzes als Schmutzgehalt der Milch berechnen.

Durchschnittlich wurden so in $1 l$ Marktmilch von Würzburg $3 \mathrm{mg}$, in solcher von Leipzig $3,8 \mathrm{mg}$, München $9 \mathrm{mg}$, Berlin $10,3 \mathrm{mg}$, Halle 14,92 mg Trocken schmutz gefunden.

Bemerkenswerth ist übrigens noch die im Anschluss hieran mitgetheilte Wahrnehmung des Verfassers, dass der überraschende Pilzreichthum der Milch nicht allein durch Verunreinigungen bedingt ist. Es dringen vielmehr bestimmte Keime in die Ausführungsgänge des Euters ein, vermehren sich dort bei der Bruttemperatur des Thierkörpers auf den zurückgebliebenen kleinen Milchresten während der Zeit zwischen den einzelnen Melkacten und werden dann beim nächsten Melken mit den ersten Milchstrahlen mehr oder weniger vollständig herausgeschwemmt. Die erste das Euter verlassende Milch ist daher verhältnissmässig sehr pilzreich.

\title{
Die Bestimmung der Wandfeuchtigkeit in neu erbauten Räumen
} besitzt erhebliche hygienische Wichtigkeit. Rudolf $\mathrm{Emmerich}^{1}$ ) hat für dieselbe nun ein Verfahren ausgearbeitet, welches einerseits den Fehler vermeidet, welcher aus der Absorption von Kohlensäure durch den im frischen Mörtel enthaltenen Aetzkalk sich ergeben könnte, andererseits mit hinreichenden Mengen Probe arbeitet und gestattet, den Wassergehalt des Mörtels in einem ganzen Zimmer in einfachster Weise zu berechnen.

$\mathrm{Zu}$ diesem $\mathrm{Z}$ wecke misst man die Mörtelfäche des Zimmers aus, und entnimmt vermittelst einer 0,5 qdm Fläche grossen Stanze durch Eintreiben derselben bis auf die Steine und seitliches Abklopfen der

1) Archiv f. Hygiene 14, 243.

Fresenius, Zeitschrift f. analyt. Chemie. XXXIr. Jahrgang. 
Stanze, von jeder Wand Mörtelproben in Form kreisrunder Scheiben von der ganzen Dicke des Mörtelbewurfs. Jede dieser Proben wird sofort in der Stanze bis zur Sonderung von Steinen und Feinmörtel zerrieben, in einem luftdicht schliessenden Glase in's Laboratorium transportirt und dort in einer flachen Nickelschale abgewogen. Behufs Trocknung bei $100^{\circ} \mathrm{C}$. werden gleichzeitig 6 solcher Proben in einen vorher angeheizten Vacuumtrockenschrank ${ }^{1}$ ) gebracht, der Deckel geschlossen und mit Hülfe der Wasserluftpumpe evacuirt. Zeigt das Thermometer im Innern $100^{\circ} \mathrm{C}$. und das Manometer der Luftpumpe, dass im Apparat Luftleere erzielt ist, so bedarf derselbe keiner weiteren Ueberwachung.

Man sieht nun nach Ablauf von einer halben bis ganzen Stunde, ob die Glasröhre des Dreiweghahnes, welcher den Vacuumapparat mit der Luftpumpe verbindet, keine Wassercondensation mehr erkennen lässt. Ist kein Hauch verdichteter Feuchtigkeit mehr zu beobachten, so wartet man noch eine Viertelstunde, lässt durch entsprechende Drehung des Dreiweghahnes von Kohlensäure und Wasser freie Luft ${ }^{2}$ ) in das Vacuum treten, nimmt den Deckel ab und constatirt nach dem Erkalten im Exsiccator den Gewichtsverlust der Proben.

Ueber den Cochenille-Carmin hat Sigmund Feitler ${ }^{3}$ ) Mittheilungen aus eignen und fremden Arbeiten gemacht, welche auch für den Analytiker Material enthalten. Der Wassergehalt von fünf verschiedenen, reinen Carminsorten betrug 17,00, 15,50, 20,48, 13,15, 15,69 (im Mittel also 16,36) Procent. Auf wasserfreie Substanz berechnet enthielten diese Carmine:

\begin{tabular}{l|c|c|c|c}
\hline \hline Bezeichnung. & $\begin{array}{c}\text { Asche } \\
\mathbf{0}\end{array}$ & $\begin{array}{c}\text { Protein- } \\
\text { Substanz } \\
0 \%\end{array}$ & $\begin{array}{c}\text { Farbstoff } 4) \\
\%\end{array}$ & $\begin{array}{c}\text { Fett } \\
\text { (Wachs) } \\
0 / 0\end{array}$ \\
\hline \hline Cochenillecarmin, echt. . & 8,1 & 24,7 & 67,2 & Spuren \\
Cochenille Naccarat. . . & 8,14 & 27,6 & 64,26 & 0,92 \\
Carmin feinst Naccarat . & 8,91 & 23,95 & 57,14 & 3,15 \\
Carmin feinst echt . . . & 10,51 & 29,00 & 60,43 & 1,18 \\
Carmin feinst echt. . . & 8,59 & 24,09 & 67,32 & 2,53 \\
\hline
\end{tabular}

1) welcher in Original abgebildet ist. Verfasser legt Werth darauf, dass die Wärme den Proben durch directe Leitung zugeführt werde, ohne dass eine Luftschicht bei dieser Leitung betheiligt ist.

2) Zu diesem Zweck ist die betreffende Oeffnung des Dreiweghahnes mit einem in bekannter Weise gefüllten Natronkalk-Chlorcalcium-Rohr verbunden.

3) Zeitschrift f. angew. Chemie 1892, S. 136.

4) Angeblich aus der Differenz berechnet, jedenfalls nach einer aus dem Original nicht ersichtlichen. Methode, da die angegebenen Zahlen nicht alle auf 100 stimmen. W. L. 